


\title{
IV. TEOrÍA SOCIAL EN LA ERA DE LO DigitAl: ENTRE LO SAGRADO Y LO PROFANO
}

\begin{abstract}
Los objetos de estudio de la ciencia social son significativos aunque no de cualquier manera, sino en sistemas de significados dobles que dan cuenta de una estructura cultural en la que el sujeto está inmerso y en medio de la cual construye sus narrativas

Reed y Alexander, European Journal of Social Theory

El futuro es nuestro mundo, el futuro es nuestro tiempo.
\end{abstract}

Agente Smith, The Matrix

En Inteligencia Colectiva, Pierre Lévy (2005) elabora una teoría de la sociedad actual fuertemente vinculada a los cambios en materia de tecnologías y saberes. Al respecto, afirma que son dos los rasgos distintivos de nuestras sociedades: primero, el número de personas llamadas a aprender y a producir nuevos conocimientos, y segundo, la aparición de nuevos instrumentos (los del ciberespacio) capaces de hacer surgir nuevas identidades y modelos socio-históricos. Este planteamiento esperanzador, en el que las relaciones sociales equivalen a relaciones de conocimiento, nos lleva a considerar que los discursos sobre las nuevas tecnologías constituyen un interesante caso de análisis epistemológico y humanístico. 
Dado que hemos venido insistiendo en la necesidad de analizar el conocimiento científico y sus manifestaciones a la luz del contexto social del que hacen parte, creemos que es importante ocuparnos del papel que se atribuye a la tecnología desde ámbitos académicos. En este sentido, una vía privilegiada para analizar el discurso tecnológico es empezar por las teorías sociales, cuyo referente es la tecnología misma.

Los relatos sobre las nuevas tecnologías suelen estar enmarcados en una retórica de cambio y novedad. En la teoría social contemporánea toma cada vez más fuerza la tesis de que vivimos un cambio de época. Este cambio de época, se afirma, está relacionado con ciertas tecnologías que han transformado las relaciones sociales de un modo nunca antes visto. Esto nos devuelve a nuestro principio rector: es pertinente llevar a cabo un análisis de los medios digitales no solo a la luz de sus dimensiones material e instrumental, sino también de su fuerza simbólica.

A lo largo de este capítulo intentaremos recrear el debate académico sobre las nuevas tecnologías y el cambio social. A nuestro juicio, dicho debate pone de manifiesto que en torno a la tecnología emergen representaciones colectivas ambivalentes. Así pues, tras revisar rápidamente los puntos más importantes del discurso sobre las nuevas tecnologías y el supuesto cambio de época actual, en la segunda parte de este capítulo abordaremos el debate académico sobre Internet. Esto nos permitirá ver con mayor detalle por qué el impacto de esta y otras tecnologías digitales no puede acabar de comprenderse sin una referencia cultural. Esperamos que el debate sobre Internet nos sirva como evidencia para argumentar que el estudio de la relación tecnología-sociedad no se puede agotar en sus dimensiones materiales, sino que se requiere de una perspectiva analítica y epistemológica fundamentalmente interpretativa.

\section{Cambio de época y tecnologías digitales}

A continuación, describiremos algunos rasgos característicos del discurso sociológico sobre las transformaciones que tienen lugar en el aspecto sociocultural. Como venimos diciendo, la tecnología aparece como principal recurso de cambio; de hecho se afirma una y otra vez que las nuevas tecnologías - las digitales, especialmente- han transformado casi todas las esferas de la vida social. Por tanto, se insiste también en la necesidad de redefinir las categorías con que se ha venido estudiando la sociedad desde el siglo XIX.

Muchos teóricos y estudiosos de la sociedad afirman que actualmente vivimos un cambio de época. A su juicio, existe una tensión creciente entre las instituciones sociales tradicionales 
y formas emergentes de poder y sociabilidad. Algunos de ellos argumentan, inclusive, que esto se debe a que el ecosistema comunicativo contemporáneo se ha transformado por cuenta de las nuevas tecnologías. Éstas han introducido cambios significativos en el acceso a la información, en los modos de comunicación y en las lógicas de consumo. Tecnología y cultura aparecen, entonces, como dos dominios interrelacionados, y constituyen el marco interpretativo del cambio de época que supuestamente viene aconteciendo.

\subsection{Transformaciones en las relaciones sociales y en sus categorías de análisis}

Los trabajos de Alberto Melucci (2001), Alain Touraine (2004; 2007), Víctor Sampedro (2011) y Manuel Castells (2012), etc., insisten en que actualmente se libra una batalla entre quienes buscan mantener el control de los comportamientos en nombre del mantenimiento del vínculo social tradicional, y entre quienes pugnan por nuevos proyectos basados en la libertad del sujeto. Prueba de esto sería la creciente influencia de redes de individuos que se alejan de lenguajes y reivindicaciones comunitaristas, mientras que, por otra parte, se advierte un giro neo-conservador en los ámbitos político y religioso. Lo que está en juego es el concepto mismo de sociedad, pues si nociones otrora vinculantes como la clase social o la ideología política entrasen en crisis, esto equivaldría a la disolución de la sociedad tal y como la hemos venido entendiendo desde el siglo XIX.

Para Melucci (2001, p. 84) urge comprender que en la actualidad "la acción colectiva no parte necesariamente de organizaciones, sino de grupos, redes y cadenas informales de individuos interrelacionados". Algo similar afirma Touraine (2004; 2007), para quien es necesario pasar de definir la vida social en términos económicos a hacerlo a partir de categorías culturales.

Según Bauman (2002; 2013), la cultura, entendida como red de símbolos socialmente compartidos, ha dejado de estar subordinada a la jerarquía social y se ha convertido en el principal recurso de construcción identitaria. Esto le lleva a concluir que para comprender la sociedad actual es necesario empezar por la cultura. Bauman advierte al respecto que ésta es intrínsecamente ambivalente. Según él, la cultura abriga significados y acciones asociados tanto a la creatividad y al cambio social como a la conservación del statu quo y al mantenimiento del orden establecido. A su juicio, la ambivalencia intrínseca de la cultura refleja con fidelidad la ambigüedad de la existencia moderna, basada en un orden racional y artificial.

En síntesis, las posiciones de estos autores sugieren que para analizar la sociedad en que vivimos se hace necesario un cambio de mirada. Según ellos, si bien estamos acostumbrados 
a pensar la sociedad en términos fundamentalmente políticos y económicos, ahora se hace pertinente hacerlo desde categorías culturales e identitarias.

\subsection{Tecnologías revolucionarias y rediseño sociocultural}

En una línea similar a las tesis de Melucci y Touraine, pero otorgando muchísima más relevancia a la variable tecnológica, la obra de Castells (2001; 2009; 2010; 2012) aborda el problema del cambio de época para afirmar la existencia de una nueva sociedad: la sociedad-red.

Según Castells $(2010 ; 2012)$, las nuevas tecnologías han permitido que la información sea actualmente el recurso principal para la búsqueda y la administración del poder. De ahí que el acceso a dichas tecnologías, así como el uso y la apropiación de determinados protocolos de participación, definan las lógicas de inclusión y exclusión del mundo actual. A su juicio, la información se ha convertido en el eje principal para la movilización de recursos.

Castells (2009) sostiene, además, que las tecnologías digitales han transformado las industrias culturales y el sistema de comunicación. Según él, gracias a ellas, las empresas globales de comunicación han logrado conectarse unas con otras, lo que ha transformado el paisaje cultural actual. Los modelos culturales básicos, resultado de esta interconexión, serían entonces: el consumismo ${ }^{1}$, el individualismo en red $^{2}$, el cosmopolitismo ${ }^{3}$ y el multiculturalismo ${ }^{4}$.

1 La cultura del consumismo, sostiene Castells, es quizás la capa fundamental de la globalización cultural al estar a la vanguardia de un mercado capitalista global. De carácter globalizado e individualista, está asociada al sector del entretenimiento global e impregna todos los niveles de las relaciones sociales, y por esa vía consigue la globalización del capitalismo.

2 Sobre este concepto se volverá más adelante. Sin embargo, valga decir que Castells (2009), Lee y Wellman (2012), consideran que el individualismo en red es el modelo de sociabilidad de la sociedadred. Para Castells, este patrón cultural encuentra su plataforma preferida en el variado universo de lo que él entiende por "autocomunicación de masas".

3 El cosmopolitismo es un modelo respaldado por actores sociales que se autodefinen ciudadanos del mundo. Según Castells, éste es un modelo que genera adhesión en las capas más jóvenes, educadas y acomodadas de la sociedad. Al pretender construir una esfera pública mundial en torno a valores comunes de ciudadanía global, el cosmopolitismo depende de las redes de medios informativos para lograr articularse.

4 Por su parte, la cultura global-multicultural se caracteriza por la hibridación y mezcla de culturas de distintos orígenes. Dice Castells (2009, p. 175) al respecto: "En nuestro mundo, el multiculturalismo es la norma, no la excepción, y por ello hay una extraordinaria diversidad de producción y distribución de contenidos culturales de este tipo". Así pues, si bien hay una capa de cultura global en todo el sector de los medios de comunicación, la mayoría de los productos culturales son más locales que globales. 
A su vez, muchas de las tesis sobre el cambio de época y la sociedad-red que plantea Castells influyen notablemente en el trabajo de Lee y Wellman (2012). Los autores sostienen que venimos presenciando el surgimiento de un nuevo sistema operativo social producto de tres revoluciones: la de las redes sociales, la de Internet, y la de los dispositivos móviles 5 . El nuevo orden social se construye en torno a Internet y las tecnologías móviles, afirman Lee y Wellman, y está planteado en una lógica de redes: el individuo está siempre conectado pero los vínculos que establece no son fijos, por lo que la identidad individual se torna flexible y adaptativa.

Por otra parte, Lash y Lury (2005) sostienen que la globalización de la economía y los adelantos de las telecomunicaciones contribuyeron al surgimiento de una industria cultural global que ha venido reordenando el sistema comunicativo y cultural. Según ellos, en la era de las industrias culturales globalizadas, la tendencia a construir la propia identidad a partir de referencias audiovisuales, literarias, musicales, etc., es cada vez más frecuente. Los medios permean, entonces, todos los nichos de la vida social.

Jenkins postula que las industrias culturales globales son solo un engranaje en el proceso de rediseño sociocultural que caracteriza al mundo actual. A su juicio, la globalización de las industrias culturales hace parte de un proceso más amplio, denominado cultura de la convergencia (Jenkins, 2008). El cambio de época que vivimos, Afirma Jenkins, no es solo el resultado de un movimiento top-down promovido por las industrias culturales. Por el contrario, distintos sectores de la sociedad se ven involucrados en la construcción de un sistema o ecología que a través de Internet transforma las lógicas con las que opera la cultura. Para Jenkins, la nuestra es una cultura

5 Lee y Wellman (2012) afirman que los movimientos de urbanización propiciados por la revolución industrial transformaron radicalmente las relaciones sociales. A su juicio, tras las grandes migraciones del campo a la ciudad, empieza a germinar una forma de organización social basada en redes, y no en clases sociales como se suele afirmar desde la sociología clásica. Los autores argumentan que solo hasta la creación de Internet, esa forma embrionaria de sociedad-red encontró una tecnología que le permitió acabar de concretarse. Según ellos, Internet ha sido una tecnología revolucionaria porque ha permitido a las personas del común mayor capacidad de comunicación, poder político y acceso a la información sin precedentes en la historia. Las tecnologías móviles (tabletas, smartphones, computación en la nube, etc.), constituyen para los autores la tercera gran revolución. Estos dispositivos y plataformas funcionan como "apéndices del cuerpo" (Lee y Wellman, 2012, p. 77) y en esa medida eliminan las barreras espacio temporales que en otro momento existían para socializar, aprender, informarse y realizar múltiples tareas. 
esencialmente mediática ${ }^{6}$, volcada al desarrollo de tecnologías que posibiliten la comunicación y la producción de contenidos.

\subsection{Una sociedad nueva: individuos conectados, cultura de compartir, y consumidores activos}

Siegel (2008, p. 17) afirma que en la actualidad vemos el mundo a través de una pantalla, y que ello ha hecho proliferar discursos basados en una "retórica triunfal y autocomplaciente". Según él, ya no se discute solamente sobre el potencial de Internet, smartphones y tabletas, sino sobre qué tipo de sociedad han producido ya.

El concepto de "individualismo en red" que aparece en los trabajos de Castells (2009; 2012), y Lee y Wellman (2012) nos introduce con mayor énfasis en la versión más optimista del discurso digital, pues sugiere la idea de que hemos llegado a una forma de organización social ideal. El individualismo en red denota un orden social en el que las personas elaboran sus relaciones sociales a partir de vínculos funcionales, libres de toda cohesión grupal. Desde esta perspectiva, la sociedad actual es una gran red de individuos conectados cuya identidad es tan dinámica y flexible como los grupos de los que hacen parte.

Un análisis más detallado de las ideas de Castells, Lee y Wellman, indica que su concepción de las relaciones sociales y de la identidad individual está inspirada tanto en una serie de metáforas computacionales como en un ideario liberal radical. Los autores plantean un modelo de organización social esencialmente autónomo, instrumental y volcado hacia la productividad, en el que la "cultura de compartir y de la participación" (Castells, 2009; Jenkins, 2009) constituyen los elementos principales del nuevo vínculo social.

Desde el discurso del individualismo en red, en el mundo "glocal" (Robertson, 2003) la comunicación se fragmenta a la hora de difundir el mensaje y se integra en el proceso de producción de significado. Según Castells, esto se debe a que las nuevas audiencias están "en el

6 Conviene comentar aquí que para Jenkins el concepto de "medio" entraña una doble significación. En plena correspondencia con el trabajo de Gitelman (2008), Jenkins (2008, p. 24) afirma: "Lisa Gitelman ofrece un modelo de medios que funciona en dos niveles: en el primero, un medio es una tecnología que posibilita la comunicación; en el segundo, un medio es un conjunto de 'protocolos' asociados o prácticas sociales y culturales que se han desarrollado en torno a dicha tecnología”. A propósito de los múltiples significados de lo mediático, el trabajo de Ardévol y compañía (2010) nos parece una referencia fundamental. 
origen de un proceso de cambio cultural, invirtiendo su dependencia histórica de los medios durante la era de la comunicación de masas" (Castells, 2009, pp. 176-178).

Según los discursos más eufóricos, el ideal del prosumidor (Toffler, 1981) ha dejado de ser parte de los ensueños de la futurología para convertirse en una realidad. Las nuevas audiencias se caracterizan por ser a la vez consumidores y productores culturales. Para Castells (2009), el fenómeno de las "audiencias creativas" es el resultado de un acceso cada vez más generalizado a Internet y a los dispositivos inalámbricos. Esto ha permitido que un número cada vez mayor de personas (especialmente jóvenes) "reivindiquen su autonomía respecto a las instituciones de la sociedad y las formas tradicionales de comunicación” (p. 181).

La siguiente afirmación de Jenkins (2008) sobre estas nuevas audiencias resume muy bien el discurso sobre el nuevo orden social basado en individuos conectados, en la cultura del compartir, y en el consumo creativo:

Si los viejos consumidores se suponían pasivos, los nuevos consumidores son activos. Si los viejos consumidores eran predecibles y permanecían donde les decías que se quedasen, los nuevos consumidores son migratorios [...] Si los viejos consumidores eran individuos aislados, los nuevos consumidores están más conectados socialmente. Si el trabajo de los consumidores mediáticos fue antaño silencioso e invisible, los nuevos consumidores son hoy ruidosos y públicos (p. 29)

Ardévol, Gómez-Cruz, Roig y San Cornelio (2010) van más allá y sostienen que en la actualidad las prácticas de consumo han trascendido su carácter de transacción económica. Según ellos, en la sociedad-red el acto de consumir remite también a ciertas "prácticas mediáticas" (Bird, 2003; Hesmondhalgh y Toynbee, 2008) a partir de las cuales los individuos redefinen lo que un producto significa socialmente. Para ellos, "lo consumido se debe entender como una apropiación creativa que implica también la manipulación y la transformación del producto y de su significado" (2010, p. 30).

En términos generales consideramos que estas lecturas sobre esta sociedad nueva, digital, hiperconectada y participativa intentan reivindicar, muy a su manera, los ideales modernos de autonomía, ilustración y libertad individual (Kant, 2012; Stuart Mill, 1985). El panorama que describen los autores citados es, grosso modo, el de unos sujetos empoderados por cuenta del "aumento de su capacidad productiva en las nuevas vías de distribución y de relación entre iguales que ofrece Internet” (Ardévol et ál., 2010, p. 29). Así mismo, se insiste en que el actual 
paisaje tecnológico ha incrementado la movilidad social y ha permitido la consolidación de formas organizativas más racionales, con arreglo a fines económicos y políticos.

A modo de conclusión provisional podríamos afirmar que, al menos en lo que atañe al discurso de la sociedad-red, las tecnologías digitales encarnan una promesa de cambio, progreso, novedad y libertad. El tono optimista de los discursos, así como los conceptos que se utilizan, nos llevan a pensar que vale la pena echar mano de un modo epistémico interpretativo para aproximarnos al discurso sociotécnico. El entusiasmo con el que la teoría de la sociedad-red se refiere a las tecnologías digitales no es un dato menor. Por el contrario, nos indica que es pertinente abordar el problema de lo digital en sus dimensiones simbólicas y narrativas. En este orden de ideas, el caso particular de Internet nos permitirá identificar los códigos en los que se enmarcan los relatos sobre el cambio de época que hemos venido analizando. Igualmente, nos ayudará a comprender mejor por qué las redes de significados que se tejen en torno a las tecnologías digitales merecen ser estudiadas con más detenimiento.

\section{El debate sobre Internet: entre el optimismo y la sospecha}

Como afirmábamos al inicio de este capítulo, nos ocuparemos específicamente de Internet porque es el símbolo de las demás tecnologías digitales, además de la plataforma sobre la que éstas funcionan. En principio, hemos de afirmar que el relato sobre Internet se estructura en torno a un código binario. En el campo de las reflexiones, teorías y estudios sociales, Internet suscita posiciones encontradas. Por este motivo, en primer lugar haremos alusión a las posturas más optimistas (las de la sociedad-red) para pasar, en segundo lugar, a comentar otras de talante más crítico. Esperamos que esto nos ayude a precisar nuestro argumento, y a justificar la perspectiva epistemológica que queremos proponer.

\subsection{Sociedad-red, Internet y salvación}

A fin de introducirnos a la versión más optimista sobre Internet, que es precisamente la de la sociedad-red, conviene volver sobre las tesis de Lee y Wellman (2012) respecto de las tres revoluciones que han dado forma al orden social actual. Según ellos, tuvimos que esperar hasta la creación de Internet para que la revolución de las redes sociales, que comenzó con la industrialización y los movimientos migratorios en masa hacia las ciudades, acabara de ser efectiva. A juicio de Lee y Wellman, las personas y el mismo sistema social requerían de 
tecnologías que les permitieran relacionarse de forma más fluida y resolver sus problemas de comunicación y coordinación. Internet, así descrito, adquiere un estatus mesiánico: su advenimiento era a la vez necesario e inevitable.

Según Castells (2001), Internet aparece cuando se coordinan tres procesos independientes: a) la progresiva globalización del capital, que generó la necesidad de modelos económicos de gestión, producción y comercio más flexibles; b) las demandas sociales de mayor libertad individual, sobre todo en el plano de la comunicación; y c) los extraordinarios avances que experimentaron la informática, las telecomunicaciones y la microelectrónica.

Castells afirma también que Internet permite a la cultura de la libertad individual, que se venía gestando desde años atrás, desarrollar todas sus posibilidades de realización material. De hecho, Internet sería la muestra perfecta de cómo los valores libertarios y modernos se encarnan en la tecnología. A su juicio, "los sistemas tecnológicos se producen socialmente y la producción social viene determinada por la cultura" (Castells, 2001, p. 51).

Así pues, la tesis sobre el origen de Internet que proponen Lee, Wellman y Castells, llevan a concluir que la Red estaba destinada a transformar la sociedad. Desde su perspectiva, una tecnología de "estructura reticular" y con "poder de computación distribuido" (Castells, 2001, p. 32) resultaba históricamente necesaria.

Según el discurso de la sociedad-red, el carácter mesiánico de Internet se refuerza por la existencia de pequeñas comunidades devotas. En principio, fueron los grupos de emprendedores contraculturales que cita Castells (2001). Luego, los blogueros, los grupos de fans y las comunidades online que refiere Jenkins $(2008 ; 2009)$. En ambos casos, estas redes de individuos serían las encargadas de mantener y promover los valores originarios de Internet, así como de explorar todas las posibilidades que entrañan sus usos políticos, económicos y culturales. Estos grupos son descritos, entonces, como innovadores, exploradores, pioneros, librepensadores y colaboradores espontáneos llamados a establecer un tipo ideal de socialización y de prácticas mediáticas. Según Jenkins (2009; 2013), estas comunidades son la prueba fehaciente de que interferir ${ }^{7}$ ya no es la única opción crítica frente a las industrias culturales; gracias a Internet también es posible participar:

7 Jenkins (2009, p. 180) define interferir como "dejar de participar en el consumo mediático y promover una concepción puramente negativa y reactiva de la cultura popular". 
La vieja retórica de oposición y captación presuponía un mundo donde los consumidores tenían poco poder directo para configurar los contenidos mediáticos y donde existían enormes barreras para entrar en el mercado, mientras que el nuevo entorno digital expande su capacidad de archivar, comentar, apropiarse de, y volver a poner en circulación los productos mediáticos (Jenkins, 2009, p. 181).

En las obras de Jenkins $(2008 ; 2009)$ es especialmente redundante la idea de que los blogueros y las comunidades de fans son testigos y misioneros del espíritu libertario y creativo que dio forma a Internet. Por un lado, los fans buscan ampliar la participación de la audiencia y su propia capacidad de interlocución en todos los procesos relativos a la producción de contenidos culturales. Por otra parte, los blogueros se han convertido, a fuerza de acción comunicativa y no de posiciones ideológicas, en e-gatekeepers, es decir, en "importantes intermediarios populares, facilitadores, no interferidores, de la transmisión" (Jenkins, 2009, p. 182).

Sin embargo, en el discurso de la sociedad-red sobre Internet, no solo destacan las comunidades dedicadas a reconvertir las dinámicas y los significados impuestos por las industrias culturales. Por otra parte, encontramos que también se hace mención de aquellos grupos que Castells (2012) denomina "redes de indignados". El término mismo con el que este autor quiere denominar las nuevas formas de acción colectiva nos introduce de nuevo en la noción de individualismo en red, esa vez trabajado desde un marco de movilización política.

A juicio de Castells (2012), Internet ha transformado las lógicas organizativas y las estrategias comunicativas de los movimientos sociales contemporáneos. Esto ha hecho que "las redes de indignados" o los "movimientos sociales en red" se caractericen por estar conectados (online), y por ser espontáneos, emocionales, virales, acéfalos y multimodales. Castells enfatiza en que sin Internet la conexión de sentimientos de indignación y solidaridad sería más difícil de producir. Para él, Internet es la columna vertebral de la acción colectiva en la sociedad-red, dada su capacidad para vehicular una "cultura de la autonomía" (p. 220).

Afirmar, sin embargo, que todos los discursos sobre Internet tienen un tono optimista, o que en todos ellos se advierte una retórica de salvación, autonomía y libertad, sería caer un reduccionismo estéril. Por el contrario, con Internet sucede algo parecido a lo que Alexander (2000) advierte en los relatos sobre el computador personal: que las esperanzas de salvación vinculadas a las innovaciones tecnológicas caminan de la mano con las grandes sombras y los miedos de nuestra época. En este sentido podríamos parafrasearle y afirmar que Internet no ha sido narrado únicamente como instrumento mesiánico, sino también como un artilugio diabólico. 


\subsection{Ciberespacio y nuevas formas control}

Si en el discurso de la sociedad-red abundan las metáforas computacionales para describir un cambio de época en el que supuestamente Internet ha jugado un papel central, mesiánico, otros autores se han mostrado críticos e incluso escépticos ante lo que consideran una posición voluntarista e ingenua.

Bauman (2002), por ejemplo, reconoce que Internet ha logrado imponerse al espacio territorial echando por tierra la noción de viaje y de distancia. Sin embargo, a medio camino entre el optimismo y el recelo, afirma:

Con la aparición de la red global de información, el espacio cibernético se ha impuesto sobre el espacio confeccionado, territorial, urbanístico o arquitectónico [...] De aquí en adelante, los obstáculos físicos y las distancias temporales no podrán separar a las gentes. Con la interfaz de los terminales de ordenadores [...] las distinciones entre aquí y allí ya no significan nada (p. 45).

Según el autor, Internet ha hecho que el ejercicio del poder se torne inestable. Si en otros tiempos dominar una cultura implicaba ejercer control sobre un código cerrado, Internet ha puesto en cuestión ese principio. De ahí que ya no sea posible ejercer un poder político y simbólico al modo industrial, en el que se vaciaba de poder a los niveles medios.

No obstante, para Bauman dicha inestabilidad resultaría problemática no solo para los Estados, sino también para los ciudadanos. El creciente descontrol en el ejercicio del poder alteraría también los procesos de consolidación de la memoria, la conciencia y la acción colectiva. Las redes sociales, por ejemplo, "crean una sensación de aproximación a la democracia directa" que termina por hacer de estas "una alternativa barata para la necesidad de actuar" (Bauman, 2013).

Por su parte, Lessig $(2006 ; 2008)$ sostiene que la promesa de libertad que trajo consigo la red global resulta hoy bastante cuestionable. A su juicio, existen razones de sobra para afirmar que Internet está siendo transformado en una herramienta de control, no de salvación. De hecho, sostiene que la sociedad civil no se ha preocupado lo suficiente por construir un código que regule Internet, dejando que instituciones comerciales y estatales rediseñen su arquitectura original en función de intereses que van en contra de las libertades civiles.

Lessig insiste en que la responsabilidad de la defensa de los valores, los protocolos de participación y los fines originales de Internet recaen sobre todos sus usuarios y no solamente sobre comunidades específicas. Para autores como Lessig (2006; 2008) y Siegel (2008, p. 13) el 
problema de fondo radica en que Internet se asume por la mayoría de la gente como una tecnología comercial, como un "prodigio de la comodidad". Esto hace que la disputa por el futuro de Internet, y de lo que implica socialmente, se libre en la mente de las personas: entre asociar Internet a una vida más fácil o asociarlo a una vida diferente. Al respecto, Lessig (2006) afirma:

Internet es un medio de comunicación. La gente hace cosas "en" Internet [...] Estos usos son importantes en el sentido de que afectan a la economía y hacen la vida más fácil o más difícil, pero no en el sentido de que alteren el modo en que vive la gente [...] El ciberespacio, en contraste, no se limita a hacer la vida más fácil: la hace diferente, o quizás mejor, dando lugar a una vida distinta [...)] El ciberespacio evoca maneras de interactuar que antes no eran posibles (p. 47).

En sintonía con Lessig, Sampedro (2006; 2006b; 2011) afirma que los progresivos controles del Estado y los mercados hacen parte de un proyecto de normalización y domesticación de las tecnologías digitales y sus usuarios. A su juicio, las crisis de control por las que pasa toda nueva tecnología siempre han sido superadas "por los usos institucionales (del poder) y las prácticas cotidianas (de las gentes) que terminan normalizando esas tecnologías, domesticándolas" (Sampedro, 2006, p. 6). Para Sampedro, la crisis del control digital, que se evidencia en las prácticas hacker y los intercambios sin fines de lucro, no tardará mucho en ser controlada. Con lo cual, el mantenimiento de las libertades inicialmente ganadas con Internet dependerá de una lucha de los usuarios contra su propio disciplinamiento (2006b).

Desde la perspectiva de Sampedro, ni la facticidad de la sociedad-red, ni la autonomía que supuestamente promueven los demás medios digitales, pueden darse por sentadas. De hecho, el autor coincide también aquí con Lessig y Bauman: afirma que la dimensión liberadora de Internet depende de la capacidad de los ciudadanos para interpelar al poder desde las posibilidades que brinda el ciberespacio y para autoorganizarse en redes que logren llevar a las personas de las pantallas a las calles (2006).

Para enfatizar en lo mucho que queda por andar para que el ideal de la sociedad-red sea un hecho, Sampedro alude a los nuevos movimientos sociales (aquellos que Castells denomina redes de indignados), y pone en entredicho el impacto de las formas virtuales de activismo. A su juicio, la influencia a largo plazo de estos movimientos online es más que dudosa, sobre todo si se tienen en cuenta los hábitos de vida de las personas que participaron. Con esto en mente, el autor concluye: "en las nuevas tecnologías la independencia de la interacción personal, respecto 
de los espacios territoriales y las conversaciones cara a cara, fomenta la irresponsabilidad y la falta de compromiso" (Sampedro, 2006b, p. 31)

Para Sampedro contrario a lo que defiende el discurso sobre el individuo en la sociedadred, "las nuevas tecnologías, tal como están institucionalizadas y tal como las usa la mayoría de la población", fomentan la irresponsabilidad cívica dentro y fuera de la red. "La presión que favorecen", continúa Sampedro "es puntual, esporádica e impredecible". Por tanto, concluye: "su virtualidad ha de entenderse también en negativo, como cualidad que expresa los serios problemas de encaje de las identidades y los mensajes que generan en el mapa de fuerzas sociopolíticas reales" (Sampedro, 2006b, p. 37).

Como se puede advertir hasta aquí, las tesis de Bauman, Lessig y Sampedro se oponen a las de Castells, Lee, Wellman y Jenkins en dos aspectos. En primer lugar, cuestionan la actualidad, validez y fuerza explicativa del discurso de la sociedad-red. En segundo lugar, afirman que para hablar de un cambio social real no basta con que las personas participen en el continuum de la producción cultural, ni que tengan acceso a Internet y demás medios digitales. Desde el discurso más crítico se argumenta que un verdadero cambio requiere que la gente se oponga a los controles que Estado y mercado ejercen sobre el ciberespacio. En este sentido, se debe sospechar de aquellas posturas teóricas que reducen el cambio social a cambio tecnológico, y que venden una idea de Internet como "la prueba y la realización definitiva de la democracia" (Siegel, 2008, p. 12).

Según los autores reseñados en esta sección, las promesas de salvación de la sociedadred son básicamente escatológicas (ya, pero todavía no). Para que dichas promesas se hagan efectivas, es necesario que las personas aprendan a relacionarse con Internet no solo desde una lógica instrumental, sino más bien desde un criterio de habitabilidad y responsabilidad. Estas críticas a los discursos más optimistas sobre Internet confirman, como sentencia Sampedro (2006b, p. 34), que existen dos miradas sobre la red:

La primera mirada identifica un conjunto de nudos entrelazados, capaces de abarcarlo todo, adaptándose y extendiéndose hasta el infinito [...] Su antónimo es la Red como conjunto de vacíos apenas unidos por un hilo.

\section{Hacia un abordaje interpretativo de las nuevas tecnologías}

Hasta aquí hemos intentado seguir algunas pistas que nos permitieran comprender mejor los discursos académicos sobre la relación entre tecnologías digitales y cambio social. Nos referimos 
en principio a las teorías del cambio de época, y pasamos de abordar la cuestión de las tecnologías digitales a examinar el caso específico de Internet.

Hemos encontrado que en torno a tecnologías como Internet se tejen tramas narrativas en clave binaria. Las posiciones frente a las tecnologías digitales en general, e Internet en particular, pasan del optimismo al desencanto. Los artilugios tecnológicos son descritos como medios para la salvación, el cambio social y la emancipación, pero también como dispositivos de control social, que refuerzan nuestra tendencia al consumismo y la indiferencia (Alexander, 2009; Reed, 2011).

La ambivalencia de los discursos sobre Internet nos confirma que las tecnologías digitales no son fenómenos puramente materiales, pues lo que significan socialmente las hace parte del sistema cultural. Desde este punto de vista, Sampedro (2006b) y Lessig (2006) tienen razón al afirmar que la batalla por el futuro de Internet se libra, sobre todo, en la mente de las personas.

La evidencia de que las tecnologías y los medios digitales no se agotan en su propia materialidad nos lleva a afinar nuestra propuesta. No basta con observar y medir; ni siquiera con sentar una posición crítica. De hecho, esto solo nos situaría en una u otra orilla del debate. Por el contrario, necesitamos comprender e interpretar lo digital en tanto discurso. De ahí la pertinencia de un enfoque epistemológico histórico-hermenéutico. Por esta vía, se podría interpretar la racionalidad técnica como un significante asociado a significados binarios que enmarcan nuestro pensamiento y nuestras prácticas mediáticas.

Lo que proponemos ahora es un itinerario de regreso. Comenzaremos hablando de Internet como símbolo y metáfora, abordaremos luego el problema de la racionalidad tecnológica y la modernidad, y terminaremos con el problema propiamente humanístico de las mediaciones estéticas y el cultivo de la sensibilidad.

\subsection{Internet como icono y metáfora}

Como se pudo advertir en la sección anterior, los relatos académicos alrededor de Internet están lejos de ser unívocos. Por el contrario, en cuanto significante, Internet inspira relatos de salvación y de control social. Esa estructura ambivalente nos indica, entonces, que vale la pena traer a colación algunos trabajos en los que se advierte cierta consciencia sobre la fuerza simbólica de las tecnologías digitales, de las cuales —insistimos - Internet es el máximo representante.

El trabajo de Cook (2006), sobre la imprenta de Gutenberg e Internet, constituye la primera de estas referencias importantes. En principio, el autor plantea que en los estudios sociales se advierte una gran fascinación con la tecnología. Esto, según él, ha influido en los análisis sobre la historia, la sociedad y la cultura. Así mismo, Cook sostiene que Internet y 
otros medios digitales han capturado la imaginación de muchos académicos, al punto de que se equipara el escenario mediático y social actual con la revolución que supuestamente se originó con la imprenta de Gutenberg.

Cook intenta probar que la denominada "revolución Gutenberg" es en realidad una construcción histórica a posteriori, imprecisa y sesgada, que otorga excesiva importancia a una sola variable de cambio (la tecnológica). Por lo anterior, se refiere a ella como "mito Gutenberg" (Cook, 2006).

La tesis del autor es que solo tras la producción de papel a gran escala y el crecimiento de la población alfabetizada, se dieron las condiciones materiales e intelectuales para que la imprenta impactase de forma significativa en la sociedad de entonces. Cook argumenta que ni el papel ni el alfabetismo dependieron de la invención de la imprenta; al contrario, hubo que esperar al siglo XIX para encontrar una masa de lectores (impulsada por el ideario de la igualdad social, la educación pública, las ideas ilustradas y las democracias liberales con su idea de ciudadanía), así como un medio de distribución (una pulpa de madera con la que hacer papel de forma realmente barata y abundante), para ser una tecnología exitosa.

La conclusión a la que llega el autor en su análisis sobre la imprenta es que aquellas lecturas sobre el cambio social articuladas en torno a una única variable gozan de gran popularidad, pese a ser reduccionistas y peligrosas. Por este motivo, según él, más allá de su veracidad, estos relatos son interesantes nichos de análisis para comprender cómo se construyen las narrativas sobre el cambio social cuando emerge una tecnología considerada novedosa.

Para Cook, "la estructura de las revoluciones tecnológicas [...] es, generalmente, la del mito Gutenberg: una tecnología en particular viene a ser la única causa de un cambio social acelerado" (Cook, 2006, p. 18). A su juicio, la década de 1980 con el ordenador, y la década de 1990 con Internet, son ejemplos cercanos de cómo la prensa popular y erudita hablaba de una tecnología que iba a revolucionar la sociedad en su conjunto. Así pues, Cook concluye:

no extraña que las discusiones actuales sobre las nuevas tecnologías reflejen el mismo tipo de distorsiones históricas y conceptuales que se encuentran en casi todas las referencias a la revolución de la imprenta [...]. El determinismo tecnológico inherente al mito Gutenberg excluye de la discusión los valores sociales, políticos y morales, que son en última instancia los únicos medios para decidir cuáles son los roles apropiados e inapropiados para las tecnologías de nuestro tiempo (Cook, 2006, p. 20). 
Por otra parte, el trabajo de Kelly (2006) sobre las metáforas computacionales también arroja luces a la discusión sobre la dimensión simbólica de Internet, y por extensión de los medios digitales. A partir de algunas afirmaciones que recuerdan el trabajo de Lakoff (2007) —en el sentido de que las metáforas hacen parte de un lenguaje cotidiano que afecta al modo en que se percibe, piensa y actúa-, Kelly argumenta que existe una tendencia fuerte a describir la realidad en términos computacionales. Esta tendencia permea, según él, las altas esferas de la ciencia, y se ha extendido al estudio del universo (sistema), del pensamiento (cálculo), de la evolución (algoritmo), de los átomos (bits) y del ADN (software), etc.

A su juicio, el éxito de las metáforas computacionales estriba en que a partir de unos códigos muy sencillos es posible describir todo tipo de fenómenos que antaño escapaban al lenguaje común. Por esta vía, el lenguaje computacional ha llegado a ser un recurso casi universal. Según Kelly, la auténtica revolución de nuestro tiempo tendría que ver, entonces, mucho menos con el acceso generalizado a computadoras y demás dispositivos, y mucho más con el uso de éstas como metáforas para referirse a casi todo.

Por su parte, Pardo (2006) afirma que la gran metáfora multipropósito no es ya la computacional sino más bien la digital. Según él, en oposición a lo mecánico y lo analógico, lo digital ha terminado por calificar todo aquello que tenga que ver con Internet y con las nuevas tecnologías. Así, a juicio de Pardo, lo digital es en la actualidad un significante cuyo significado se sobreentiende sin ser preciso.

El trabajo de Feenberg (2012) sugiere que el impacto de Internet no se limita a unos cambios observables en los sistemas de comunicación sino que, en cuanto ícono tecnológico, Internet estimula lecturas y relatos sobre el pasado, el presente y el futuro de la humanidad. A su juicio, los giros en la teoría social desde la década de 1970 hasta el presente son un claro ejemplo de cómo se construyen los vínculos entre las narrativas tecnológicas y la conciencia colectiva de una época.

Feenberg afirma que las teorías de Heidegger (1960) y Marcuse $(1968$; 1972) reflejan bastante bien una primera forma dominante de posicionamiento ante la tecnología. Durante un periodo que se extendió desde el Mayo francés y las contraculturas hasta la caída del Muro de Berlín, el autor advierte una actitud intelectual más bien pesimista. Las reflexiones surgidas en este periodo reforzaban la idea de que las condiciones de la vida moderna poseían una alienante apariencia de racionalidad que las tecnologías de ese entonces vehiculaban, producto de lo cual sería una sociedad de audiencias masivas.

Más adelante, sostiene Feenberg, hacia el final del siglo XX, las computadoras en red rompieron ese patrón de reflexión teórica. Frente a la pasividad de las audiencias tradicionales de medios de masas, desde diversos frentes académicos se comenzó a hablar de sujetos 
interconectados. La teoría social adquirió un tono más optimista, e intentó deslegitimar la crítica distópica de carácter especulativo a través de multitud de estudios empíricos. Sin embargo, advierte el autor, pareciera que con el paso del tiempo el discurso sobre Internet y lo nuevo de las nuevas tecnologías se ha vuelto predecible y tedioso, como sucedió en su momento con las teorías más críticas.

\subsection{Modernidad, razón y tecnología}

Del trabajo de Feenberg (2010) se infiere que el efecto de puerta giratoria entre posiciones aparentemente irreconciliables da cuenta de un debate que no empieza ni termina con las tecnologías digitales. De hecho, el autor encuentra que las teorías -críticas, inclusive- de la modernidad dependen en exceso del concepto de racionalización para explicar los procesos de producción tecnológica y los rasgos particulares de las sociedades modernas (progreso, ilustración, diferenciación funcional, etc.).

Según Feenberg, los teóricos de la modernidad se han visto casi que obligados a otorgar a la tecnología un estatus de racionalidad pura. De ahí, a la tecnología se le atribuye una materialidad objetiva, se la ubica en el centro de la acción instrumental, y termina siendo garantía de progreso. De la conjunción de estos elementos emerge, paradójicamente, un nuevo mito: el determinismo tecnológico, que inunda por igual la teoría social y la cultura popular. Y es que si se mira con detenimiento, tanto el discurso de la sociedad-red como las críticas a éste parecen tener un guion parecido al de los anuncios de tabletas, celulares, y a al cine de ciencia ficción. Si por un lado advertimos un proceso deliberado de "crear fascinación" (Berger, 2010), por otro se critica el presente y se pone en tela de juicio el futuro para "reflejar y amplificar los grandes miedos de nuestro tiempo" (Musset, 2008).

En este sentido, la gran paradoja del discurso moderno es que, en su afán por pasar del mito al logos, termina por hacer de la racionalidad tecnológica su mito fundacional. Solo así se explica que el imaginario social sobre la tecnología oscile entre visiones apocalípticas e integradas (Eco, 2004). A juicio de Feenberg, esta es la mayor evidencia de que una perspectiva de análisis hermenéutica podría garantizar mejores resultados que los modelos nomológicos derivados de la física, suponiendo que nos interese comprender la relación compleja entre sociedad, cultura y tecnología.

Un enfoque de trabajo interpretativo, por tanto, contribuye a evitar el error de reducir la tecnología a sus elementos racionales y a su condición material. Estudiar la tecnología como si se tratase de un texto (Alexander, 2009) introduce una perspectiva teórica más amplia, 
multidimensional. Así, en lugar de suponer que la racionalidad y la medición son los únicos criterios para analizar el fenómeno tecnológico, valdría la pena estudiar la racionalidad tecnológica y las tecnologías digitales entendiéndolas como reflejo de una red de símbolos. No podemos olvidar que es, precisamente, en el plano cultural donde se discute cuáles son los usos apropiados e inapropiados, legítimos e ilegítimos, de la tecnología (Cisneros y Pérez, 2000).

\subsection{Retorno a las humanidades: sensibilidad estética y cultivo de la percepción}

Inevitablemente, el problema de la interpretación nos remite de nuevo a cuestiones humanísticas, en concreto a la importancia de aprender a percibir. Desde un horizonte estético y filosófico, Molinuevo (2004; 2007b; 2008) aporta unas ideas bastante valiosas. A juicio del autor, no solo se debe considerar la omnipresencia física de las nuevas tecnologías, sino también la gran cantidad de imágenes tecnológicas con que nos topamos a diario. Según él, la cultura del siglo XXI es fundamentalmente visual, por lo que se hace imprescindible volver sobre el ideal humanístico de formar el juicio y la sensibilidad.

Para Molinuevo, la proliferación ininterrumpida de imágenes tecnológicas hace que todo proyecto interpretativo estribe en la capacidad de percibir el entorno y de crear mediaciones conceptuales que permitan un juicio reflexivo sobre el mundo actual. En este sentido, urge reconocer que las imágenes que constituyen nuestro entorno tienen el poder de educar, de reforzar conceptos emocionales, y de generar vínculos identitarios. Así pues, según Molinuevo:

En una época de cambio acelerado se vuelve urgente la necesidad de percibir el entorno. Nuestros entornos reajustarán nuestros umbrales sensoriales. Y estos, a su vez, afectarán más tarde a nuestras perspectivas y expectativas (2004, p. 193).

Él insiste, entonces, en que solo desde un proyecto educativo que pretenda formar una nueva sensibilidad será posible hacer contrapeso al individualismo de masas. Para ello, sostiene, se debe tener muy presente la premisa adorniana (Adorno, 2004) de una mediación estética, que haga de puente entre el pensamiento y las nuevas tecnologías.

Para Molinuevo, las mediaciones estéticas son totalmente necesarias porque la cultura de las nuevas tecnologías está fundamentada, en no pocos casos, en una temporalidad irreflexiva. Según él, vivimos en una cultura visual de ciclos cada vez más cortos de relevo tecnológico, lo que hace que las imágenes, las metáforas y los conceptos con que se busca entender la tecnología queden obsoletos rápidamente. 
A juicio de Molinuevo (2008), hay todo un "misticismo asociado a lo digital" que debe empezar a analizarse. Dicho misticismo se mantiene gracias a la creencia de que "las nuevas tecnologías son el mito de la eterna juventud”. Según él, mientras en el plano ético o político la idea de progreso ha sido ampliamente discutida, en el ámbito tecnológico se sigue considerando que "cada tecnología es mejor que las anteriores", por lo que la novedad termina convertida en "un valor seguro que enseguida hace viejo lo anterior".

Si se reconoce, entonces, que la cultura de las tecnologías opera a través de la construcción de imaginarios (Molinuevo, 2008) sobre los que se suele reflexionar más bien poco, resulta que las mediaciones estéticas, y no el acceso o el uso competente de las tecnologías digitales, vendría a ser la cuestión más urgente sobre la que tiene que trabajar, por ejemplo, la educación.

A nuestro parecer, la propuesta de Molinuevo reviste de una importancia especial porque profundiza en la idea de situar el debate en un plano decididamente cultural. Su tesis de que en la actualidad adquirir tecnologías y aprender a usarlas se antoja menos importante que aprender a percibir el entorno, discutir conceptos, e interpretar imágenes, nos parece refrescante y lúcida. En síntesis, podríamos decir que el debate sobre el lugar social de la tecnología se debe dirigir hacia la necesidad de formar la percepción y la sensibilidad respecto de las dimensiones no materiales del fenómeno tecnológico. Como decíamos al principio de este libro, en muchos casos, académicos y vitales, de lo que se trata es de intentar, como Leono, ver más allá de lo evidente.

\section{Referencias}

Adorno, T. (2004). Teoría estética. Madrid: Akal.

Alexander, J. C. (2000). La promesa de una sociología cultural. Discurso tecnológico y la máquina de la información sagrada y profana. En Sociología cultural: formas de clasificación en las sociedades complejas. México, D. F.: Flacso-Anthropos.

Alexander, J. C. (2009). What We Learn from the Humanities? Newsletter of Sociology of Culture, 23 (1), 4-8.

Ardévol, E., Gómez-Cruz E., Roig, A. y San Cornelio, G. (2010). Prácticas creativas y participación en los nuevos media. Quaderns del CAC, 34(13), 27-38.

Berger, J. (2010). Modos de ver. Barcelona, Gustavo Gil.

Berman, B. (productor); Wachowski, A. y Wachowski, L. (directores) (1999). The Matrix. Warner (DVD). Bauman, Z. (2002). La cultura como praxis. Buenos Aires: Paidós. 
Bauman, Z. (2013). Zygmunt Bauman opina sobre las redes sociales. El Universal. Recuperado de: http:// www.eluniversal.com.mx/notas/915373.html

Carr, N. (2008). Is Google Making Us Stupid? What the Internet is doing to our brains. The Atlantic. Recuperado de: http://www.theatlantic.com/magazine/archive/2008/07/is-google-making-us-stupid/306868/

Carr, N. (2010). Superficiales. ¿Qué está haciendo Internet con nuestras mentes? Madrid, Taurus.

Castells, M. (2001). La galaxia Internet. Barcelona: Plaza \& Janés.

Castells, M. (2009). Comunicación y Poder. Madrid: Alianza.

Castells, M. (2010). Network Theories of Power. International Seminar on Network Theory, Marzo, USC Anneberg School for Communications.

Castells, M. (2012). Redes de indignación y esperanza: los movimientos sociales en la era de Internet. Madrid: Alianza.

Cook, N. (2006). Technological Revolutions and the Gutenberg Myth. En Hassan, R. and Thomas, J. (eds.). The New Media Theory Reader. New York: Open University Press y McGraw-Hill Education.

Eco, U. (2004). Apocalipticos e Integrados. Barcelona: Lumen.

Feenberg, A. (2010). Between Reason and Experience. Essays in Technology and Modernity. Cambridge: The MIT Press.

Gitelman, L. (2008) Always Already New: Media, History and the Data of Culture. Edición Kindle. Disponible en Amazon.com

Heidegger, M. (1960). Serenidad. Eco, Revista de la Cultura de Occidente, agosto, 24-50.

Jenkins, H. (2008). Convergence Culture. La cultura de la convergencia de los medios de comunicación. Barcelona: Paidós.

Jenkins, H. (2009). Fans, Blogueros y Videojuegos. La cultura de la Colaboración. Barcelona: Paidós.

Kant, I. (2012). Contestación a la pregunta: ¿Qué es la ilustración? México, D. F.: Taurus.

Kelly, K. (2006). The computational metaphor. En Hassan, R. and Thomas, J. (eds.). The New Media Theory Reader. New York: Open University Press, McGraw-Hill Education.

Lakoff, G. (2007). No pienses en un elefante. Madrid, Editorial complutense.

Lash, S. and Lury, C. (2007). Global Culture Industry, The Mediation of Things, Cambridge: Poliry Press.

Lee, R. y Wellman, B. (2012). Networked. The New Social Operating System. MIT Press: Cambridge MA. Edición Kindle, disponible en Amazon.com

Lessig, L. (2006). El código 2.0. Madrid: Traficantes de sueños.

Lessig, L. (2008). Remix: Making art and commerce thrive in the hybrid economy. New York: Penguin.

Lévy, P. (2004). Inteligencia colectiva: por una antropología del ciberespacio. Washington, D. C.: Organización Panamericana de la Salud.

Marcuse, H. (1968). El hombre unidimensional. Barcelona: Seix Barral. 
Marcuse, H. (1972). Razón y Revolución. Madrid: Alianza.

Melucci, A. (2001). Vivencia y convivencia. Teoría social para una era de la información. Madrid: Trotta. Stuart Mill, J. (1985). Sobre la libertad. Madrid: Orbis.

Molinuevo, J. L. (2004). Humanismo y nuevas tecnologias. Madrid: Alianza.

Molinuevo, J. L. (2006). La vida en tiempo real. La crisis de las utopias digitales. Madrid: Biblioteca Nueva.

Molinuevo, J. L. (2007). Hacia un lenguaje de la ciudadanía en las nuevas tecnologías. Argumentos de Razón Técnica, 10, 43-54.

Molinuevo, J. L. (2007b). De las utopías digitales a las utopías limitadas. I conferencia internacional Ciudadanía y Derechos digitales. Gobierno electrónico y nuevos derechos humanos. Madrid, 30 de octubre.

Molinuevo, J. L. (2008). Nuevos tiempos en la estética de las nuevas tecnologías. La eterna juventud. TELOS, 76. Recuperado de http://telos.fundaciontelefonica.com/telos/articulocuaderno.asp@ idarticulo $=12 \& \mathrm{rev}=76 . \mathrm{htm}$

Pardo, H. (2010). Geeknomía. Un radar para producir el posdigitalismo. Barcelona: Publicacions i Edicions de la Universitat de Barcelona.

Reed, I. (2011). Interpretation and Social Knowledge: On the Use of Theory in the Human Sciences. ChicagoLondon: University of Chicago Press.

Reed, I., y Alexander, J. (2009). Social Science as Reading and Performance. A Cultural-Sociological Understanding of Epistemology. European Journal of Social Theory, 12(1), 21-41.

Robertson, R. (2003). Glocalización: tiempo-espacio y homogeneidad-heterogeneidad. En Mongenegro, J. C. Cansancio del Leviatán: problemas políticos de la mundialización. Madrid, Trotta.

Sampedro, V. (2006a). Ciberactivismo: Estrategias de futuro en clave de presente (sin olvidar el pasado). En VV.AA. Manual de ciberguerrilla, pp. 5-14. Barcelona: Virus.

Sampedro, V. (enero-marzo, 2006b). ¿Redes de nudos o vacíos? Nuevas tecnologías y tejido social. Documentación social, 140, 25-38.

Sampedro, V. (2011). Públicos y recursos tecnopolíticos. Minorías insatisfechas y diques a la participación.

En Sampedro, V. (Coord.). Cibercampaña. Cauces y diques a la participación. Las elecciones generales de 2008 y su proyección tecnopolitca. Madrid: Editorial Complutense.

Siegel, L. (2008). El mundo a través de una pantalla. Ser humano en la era de la multitud digital. Barcelona, Urano.

Toffler, A. (1981). The third wave. New York: Bantam books.

Touraine, A. (2004). Un nuevo paradigma para comprender el mundo de hoy. Barcelona: Paidós.

Touraine, A. (2007). Sociology after sociology. European Journal of Social Theory, 10(2), 184-193. 